examination of the counties of Kent, Surrey, and Sussex, of which an outline has been given above, are as follows:-

(1). That on pervious soils there is less consumption than on impervious soils.

(2). That on high-lying pervious soils there is less consumption than on low-lying pervious soils.

(3). That on sloping impervious soils there is less consumption than on flat impervious soils.

(4). These inferences must be put along with the other fact, that artificial removal of subsoil-water, alone, of various sanitary works, has largely decreased consumption.

From which follows the general inference, that werness of sorm IS A GREAT CAUSK OF CONSUMPTION, no other condition having been found, in the course of these inquiries, to go along with the consumption death-rate to any great extent.

The value of such a conclusion, should it stand the test of further examination, cannot I think be over-estimated. It would introduce a new principle and object into the carrying out of those drainageworks that have been so much called for of late; it would aid consumptive people in choosing healthy living-places, and in avoiding those that may be hurtful; it would lead to the lessening of a disease that is the special curse of our country; and, by bringing men of science something nearer to the knowledge of the first cause of consumption, it might lead to the discovery of that cause, and of such treatment and remedies as would successfully grapple with the disease.

Confirmatory and independent evidence of the truth of the above conclusion comes to us from America, Dr. Bowditch having drawn attention, in 1862, to the fact that "medical opinion in Massachusetts .... tends strongly to prove .... the existence of a law in the development of consumption in Massachusetts . . . . that dampness of the soil . . . . is intimately connected, and probably as cause and effect, with the prevalence of consumption." 1 The Registrar-General for Scotland, quoting the above (in his Seventh Annual Report), and applying it to eight large towns in Scotland, accepts the theory. It is right to add however that no such detailed examination, as in our case, seems to have been made in either America or Scotland.

\title{
IVOTICFS OF MEMOIRS.
}

\section{I.-Fxperments on Contortion of Mountatn Limestone. ${ }^{2}$}

\section{By Louis C. Mrati, Esq.}

T'T has been well established by numerous experiments that no I rigid body is either quite inflexible or perfectly elastic. All

1 "Consumption in New England and elsewhere, or Soil-moisture one of its chief causes." Ed. 2. Boston, 1868. I should state that Dr. Buchanan did not know of this pamphlet until the completion of his own researches.

2 Read before the British Association (Section C.) at Exeter, August, 1869. 
bodies are altered in form by pressure, and every change of form produces some permanent alteration, however slight, either in shape or texture. When any substance is bent, the total deflection is made up of two elements, which may be termed elasticity and set, or tomporary and permanent deflection.

The practical importance of this distinction in iron-work has led to valuable investigations respecting the changes produced in that metal by strains. Mr. Hodgkinson and Mr. Fairbairn have prepared tables which give the results of many experiments of this kind. More recently, M. Tresca has investigated the subject, and his paper on the "Flow of Solids," read before the Institution of Mechanical Engineers at Paris in 1867, contains an account of various experiments instituted to prove that the behaviour of liquids under pressure is only one case of a general law, which may be extended to solids also, being of course particularly conspicuous in those solids which, like iron and lead, possess a marked duotility.

The geologist is aware that rocks also are capable of both temporary and permanent deflection. Contorted rocks; of which a vast number of examples are known, shew that in many cases compact and solid strata have been crumpled up like folds of cloth, while the contained fossils have been occasionally curiously distorted, yet without fracture. It is quite unnecessary to cite instances of what is well-known to all students of geology. From the earliest days of the science these phenomena have been referred, and no doubt justly, to slow and long continued pressure. But I am not aware that the matter has ever been investigated with quantitative precision, and the experiments which I am about to quote were accordingly directed to this issue-an exact comparison of sudden and continuous strains with reference to the deflection which they can respectively produce.

The apparatus which has been contrived to prosecute this inquiry is of a simple kind. The machine here exhibited is adapted for producing visible deflection in thin slabs of stone. The lamina is clamped at one end of a block, the length to be bent is regulated by sliding the block along a groove, and a known weight descends upon the free end. Provision is made that the weight shall act upon a knife-edge, which is always perpendicular to the surface of the slab and always applied to the same line. By means of an index, the deflection can be read accurately to hundredths of an inch.

With this apparatus I have made experiments for some months past, but the process is so slow, several weeks being required for one operation, that the results hitherto arrived at are very limited. I have as yet tested carefully no material except mountain limestone, and there is still much to be done in studying the effect of small but long continued strains upon that substance.

The annexed table gives the results of one series of contortion experiments. A number of observed facts have been neglected in order to give prominence to the chief point, viz. the difference in the deflections which may be produced by the sudden application of a considerable weight and the prolonged action of slight pressure. The 
angles have been deduced from the amount of perpendicular deflection, and they are consequently all taken as rectilinear.

\section{Experiments on Contortion of Mountain Limestone.}

No. 1. $\frac{7}{100}$ in.

\begin{tabular}{|c|c|c|c|}
\hline $\begin{array}{l}\text { 2lbs. } \\
\text { Immediately } \\
\text { (broke at) } 2 \cdot 2^{\circ}\end{array}$ & $\begin{array}{c}7 \mathrm{oz} . \\
3 \text { weeks } \\
7 \cdot 4^{\circ}\end{array}$ & 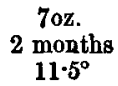 & $\begin{array}{c}\text { Recovered in } \\
3 \text { weeks } \\
2 \cdot 7^{\circ}\end{array}$ \\
\hline
\end{tabular}

No. 2. $\frac{6}{100}$ in.

\begin{tabular}{c|c}
$\begin{array}{c}\text { 2lbs. } \\
\text { Immediately }\end{array}$ & $\begin{array}{c}70 z . \\
\text { (broke at) } 2 \cdot 5^{\circ}\end{array}$ \\
$8 \cdot 15^{\circ}$
\end{tabular}

No. 3. $T^{\frac{\gamma}{00}}$ (bituminous).

\begin{tabular}{|c|c|c|c|}
\hline $\begin{array}{l}\text { 2lbs. } \\
\text { Immediately } \\
\text { (broke at) } 2 \cdot 75^{\circ}\end{array}$ & $\begin{array}{c}70 z . \\
3 \text { weeks } \\
7 \cdot 65^{\circ}\end{array}$ & 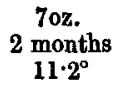 & $\begin{array}{c}\text { Recovered in } \\
3 \text { weeks } \\
3 \cdot 1^{\circ}\end{array}$ \\
\hline
\end{tabular}

No. 4. T 90 (bituminous).

\begin{tabular}{c|c|c|c} 
2lbs. & $50 z$. & $50 z$. & Broke after \\
Immediately & 3 weeks & 3 weeks & 11 days \\
(broke at) $2 \cdot 15^{\circ}$ & $7 \cdot 1^{\circ}$ & $12 \cdot 5^{\circ}$ &
\end{tabular}

Another circumstance connected with these experiments has some interest in connection with geological phenomena. I have found repeatedly that the slabs, when bent to any considerable angle, have exhibited a great tendency to break transversely. This has generally appeared some days after the strain was removed. In those cases where sharp, unbroken bends occur in rocks, the tendency to fracture has been probably overcome by the pressure of superincumbent mass. As yet I have not been able to imitate the natural conditions so as to verify this explanation experimentally, but I have no doubt of its correctness. In one well-marked instance in the Mountain limestone district of Yorkshire an anticlinal flexure passes eastwards into an anticlinal fault with gradually increasing displacement. The geological evidence in this case shews unmistakably that the limestone was covered at the time of disturbance by a considerable thickness of upper Carboniferous strata, which are also known to have materially diminished eastwards,- that is, in correspondence with the alteration in the character of the anticlinal.

Some interesting facts have been observed by the microscopic examination of the deflected substances, but these results require more complete investigation. In order to operate upon thicker slabs, I am preparing a micrometer screw which will read deflection to 1-1500 inch. At some future time I hope to bring a fuller collection of observations under the notice of geologists. 


\section{II.-On Certain Phenomena in the Drift natar Norwioh.}

By JoHN E. TAYLOR, Esq.

TT has been well observed that in Norfolk we possess the best 1 graduated series of later deposits from the Pliocene age upwards, to be found in Great Britain. With the exception of the "Purple Clay," found by Messrs. Wood and Rome in Lincolnshire, and believed by them to be of later date than the upper Boulder-clay of Norfolk, we have all the Pleistocene series complete. Notwithstanding this, there are few "debateable lands" more open to difference of opinion than those of Norfolk. Every now and then, the geologist who believes he has made out a complete case, and imagines he can rest on his oars, is suddenly disturbed by some out-of-theway and apparently trivial discovery which upsets all his previous calculations, and forces him to his Sisyphus task again. I believe, however, that ultimately all these discrepancies will be found more fully to bear out the glacial hypothesis.

I have the honour to bring before the notice of this Section several phenomena which apparently disturb the succession of the drift-beds, but which in my opinion only confirm the theory of their origin. About three years ago, my friend Mr. Harmer, of Norwich, contributed a paper which was read before the Geological Society of London, on a "third, or Valley Boulder-clay." This deposit was found at Thorpe, near Norwich, and Mr. Harmer, who I believe has since altered his hypothesis, gave to it its name of "Valley BoulderClay," from finding it on the shoulder of the high grounds bounding the valley of the Yare towards the east. Subsequently I conducted Mr. Harmer to a similar deposit at Swainsthorpe, aboui five miles from Norwich, where the Boulder-clay is seen resting on the reconstructed Chalk, to the absence of the intervening series, which, however, are found to the north and south of this patch, at the distance of less than a quarter of a mile. All these beds occur on a plateau, away from any river valley. Again, at Harford Bridges, two miles from Norwich, a similar bed of Boulder-clay is seen lying at a lower level than the middle drift sands which occur about a quarter of a mile off. Last year, in company with Professor Liveing and the Rev. Osmond Fisher, I visited this bed, in order to point out the seeming anomaly, when Mr. Fisher suggested what I believe to be the true explanation in every case where the upper Boulder-clay lies out of its true position-that it had been thrown down in a deep furrow or groove formed by the stranding of an iceberg. Some of the localities where the phenomena I am about to mention occur, may have been in a continuous line of such iceberg action, and the intervening area may have been denuded into its present form, so as to cut off the connection.

In the cutting of a deep railway gulley, close by the well-known Crag-pit of Thorpe, near Norwich, there was laid open, about a couple of years ago, a section showing a north-easterly groove scooped out of the sand and pebble-beds, and having the Upper

1 Read before the British Association (Section C.), Exeter, August, 1869. 
Boulder-clay dropped into it. The diameter of the furrow was about a hundred yards. On each side the sands were twisted and contorted, as though they had been acted upon by some moving mass, and thrown out of their original position. The Boulder-clay at Harford Bridges evidently rests on the disturbed Chalk, which comes up a little nearer Norwich, on the same side of the river. This bed cannot be more than two or three hundred yards in breadth, and it also has a north-easterly extension. On the higher grounds of Trowse and Bixley, the Upper Boulder-clay may again be seen resting on the disturbed Chalk, although less than a quarter of a mile away, in the same line of high ground, there is a pit where the Crag is developed, with the pebble-beds and clays overlying it, the whole resting on the hard and undisturbed Chalk. Mr. Searles Wood, in a paper read before the British Association at Norwich, last year, stated what he called an "anomalous structure in the Upper Glacial beds." This was that the true Boulder-clay in the centre of Norfolk has been deposited in a great trough more than twenty miles in breadth. It is evident that this has no connection with the minor phenomena I have endeavoured to describe, although this great sheet also is let down on the Chalk. Such an extensive result may, however, be directly connected with the general glaciation of the Norfolk Chalk-beds.

At Drayton, about three miles from Norwich, and again at Attlebridge, about four miles further, the same phenomenon of the grooving of the Lower Drift-beds and the deposition of the Boulderclay in the hollow, may also be seen, although here the surface of the country must have suffered considerable denudation since it occurred. In none of these instances is the width of the Boulder-clay deposit more than a few hundred yards. Another phenomenon seems to have more or less of a connection with those I have described. Close by the patch of Boulder-clay at Swainsthorpe, and on the same general level, the re-deposited Chalk crops up, and the flint bands may be seen contorted and dragged up into an angle of nearly sixty degrees. At Whitlingham, between the patches of Boulderclay, lying out of their true places at Thorpe and Trowse, there is a fine section showing the flint bands in the disturbed Chalk thrown into quite an anticlinal axis, although a few hundred yards to the right and left of the same bed, they are in almost their original horizontality. It would seem as if the agent which had furrowed and displaced the Lower Drift-beds, and caused the Upper to be deposited in the hollow, had also dragged up and twisted the flintbands in the Chalk along its course, just as I have mentioned its having contorted the sand-beds in the railway cutting. The occurrence of the two phenomena so near together is certainly suggestive. If the Upper Boulder-clay was formed under glacial-marine conditions, the stranding of icebergs must have been of frequent occurrence, so that phenomena like those I have mentioned only prove the general fact. Thus viewed, these seeming anomalies fall into their proper places, and complete the evidence of the semi-arctic circumstances under which some of the Drift-beds of Norfolk were accumulated. 